\title{
Lesão muscular: Fisiopatologia, diagnóstico e tratamento*
}

\section{Muscle Injury: Pathophysiology, Diagnosis, and Treatment}

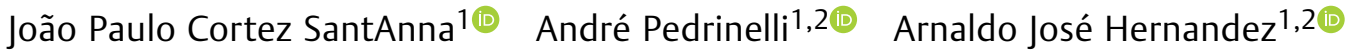 \\ Tiago Lazzaretti Fernandes ${ }^{1,2}$ (D) \\ ${ }^{1}$ Grupo de Medicina do Esporte, Instituto de Ortopedia e \\ Traumatologia, Hospital das Clinicas, Faculdade de Medicina, \\ Universidade de São Paulo, São Paulo, SP, Brasil

\begin{abstract}
Endereço para correspondência Tiago Lazzaretti Fernandes, PhD,
\end{abstract} \\ Rua Dr. Ovídio Pires de Campos, 333, $2^{\circ}$ andar (LEM) - 05403-010 - São \\ Paulo, SP, Brasil (e-mail: Tiago.lazzaretti@usp.br).
}

${ }^{2}$ Centro de Excelência Médica da FIFA, São Paulo, SP, Brasil

Rev Bras Ortop 2022;57(1):1-13.

\begin{abstract}
Resumo
Palavras-chave

- sistema musculoesquelético/ fisiopatologia

- sistema musculoesquelético/ lesões

- sistema musculoesquelético/ cirurgia

- regeneração

O tecido muscular esquelético possui a maior massa do corpo humano, correspondendo a $45 \%$ do peso total. As lesões musculares podem ser causadas por contusões, estiramentos ou lacerações. A atual classificação separa as lesões entre leves, moderadas e graves. Os sinais e sintomas das lesões grau I são edema e desconforto; grau II, perda de função, gap e equimose eventual; grau III, rotura completa, dor intensa e hematoma extenso. O diagnóstico pode ser confirmado por ultrassom (dinâmico e barato, porém examinador-dependente); e ressonância magnética (RM) (maior definição anatômica). A fase inicial do tratamento se resume à proteção, ao repouso, ao uso otimizado do membro afetado e crioterapia. Anti-inflamatórios não hormonais (AINHs), ultrassom terapêutico, fortalecimento e alongamento após a fase inicial e amplitudes de movimento sem dor são utilizados no tratamento clínico. Já o cirúrgico possui indicações precisas: drenagem do hematoma, reinserção e reforço musculotendíneos.
\end{abstract}

\footnotetext{
Trabalho realizado no Laboratório de Investigação Médica do Sistema Musculoesquelético - LIM41 do Departamento de Ortopedia e Traumatologia da FMUSP, Grupo de Medicina do Esporte do Instituto de Ortopedia e Traumatologia (IOT) do Hospital das Clínicas da FMUSP e Centro de Excelência Médica da FIFA.
}

recebido

06 de Outubro de 2020

aceito

08 de Março de 2021

Publicado on-line

de Janeiro 22, 2022
DOI https://doi.org/ 10.1055/s-0041-1731417. ISSN 0102-3616. (c) 2022. Sociedade Brasileira de Ortopedia e Traumatologia. All rights reserved.

This is an open access article published by Thieme under the terms of the Creative Commons Attribution-NonDerivative-NonCommercial-License, permitting copying and reproduction so long as the original work is given appropriate credit. Contents may not be used for commercial purposes, or adapted, remixed, transformed or built upon. (https://creativecommons.org/ licenses/by-nc-nd/4.0/)

Thieme Revinter Publicações Ltda., Rua do Matoso 170, Rio de Janeiro, RJ, CEP 20270-135, Brazil 

Abstract
Keywords
- musculoskeletal system/ physiopathology
- musculoskeletal system/injury
- musculoskeletal system/surgery
- regeneration

Skeletal muscle tissue has the largest mass in the human body, accounting for $45 \%$ of the total weight. Muscle injuries can be caused by bruising, stretching or laceration. The current classification divides these injuries into mild, moderate and severe. The signs and symptoms of grade I lesions are edema and discomfort; grade II, loss of function, gaps and possible ecchymosis; and grade III, complete rupture, severe pain and extensive hematoma. The diagnosis can be confirmed by ultrasound, which is dynamic and cheap, but examiner dependent; and magnetic resonance imaging (MRI), which provides better anatomical definition. The initial phase of the treatment consists in protection, rest, optimal use of the affected limb, and cryotherapy. Nonsteroidal anti-inflammatory drugs (NSAIDs), ultrasound therapy, strengthening and stretching after the initial phase and range of motion without pain are used in the clinical treatment. On the other hand, surgery has precise indications: hematoma drainage and muscle-tendon reinsertion and reinforcement.

\section{Introdução}

As lesões musculares são a causa mais frequente de incapacidade física na prática esportiva. Estima-se que entre $30 \mathrm{e}$ $50 \%$ de todas as lesões associadas ao esporte são causadas por lesões de tecidos moles. ${ }^{1}$ Tal incidência pode ser mais elevada de acordo com o esporte. No atletismo e no futebol, cerca $\sim 30$ a $41 \%$ de todas as lesões são musculares, ${ }^{2-4}$ enquanto no levantamento de peso, as lesões musculares representam até $59 \%$ das injúrias. ${ }^{5}$

Apesar de o tratamento não cirúrgico resultar em bom prognóstico na maioria dos atletas com lesão muscular, as consequências da falha do tratamento podem ser dramáticas, postergando o retorno à atividade física por semanas ou até mesmo meses. ${ }^{6} \mathrm{O}$ conhecimento de alguns princípios básicos da regeneração e dos mecanismos de reparo do músculo esquelético pode ajudar a evitar perigos iminentes e acelerar o retorno ao esporte.

\section{Anatomia e biomecânica}

As fibras musculares geralmente se originam em um osso ou tecido conectivo denso e se inserem em outro osso através de uma inserção tendínea.

Há músculos que atravessam uma ou mais articulações para gerar movimento. Os músculos com função tônica ou postural geralmente são uniarticulares, largos, planos, com velocidade de contração baixa e com capacidade de geração e manutenção de força contrátil grande. Geralmente, estão localizados nos compartimentos mais profundos.

Os músculos biarticulares têm velocidade de contração e capacidade para mudança de comprimento maiores; contudo, possuem menor capacidade de suportar tensão. Geralmente, estão localizados em compartimentos superficiais.

Quanto à forma, os músculos fusiformes permitem uma maior amplitude de movimento, enquanto os músculos penados têm maior força contrátil.

O comprimento da fibra é um determinante importante da quantidade de contração possível no músculo. Como as fibras musculares geralmente apresentam distribuição oblíqua dentro de um ventre muscular, elas geralmente são menores do que o comprimento total do músculo.

\section{Mecanismos de lesão}

A causa da lesão muscular pode ser considerada indireta ou direta. ${ }^{7}$ A lesão indireta é relacionada a ausência de contato. Pode ser de causa funcional, por sobrecarga mecânica ou lesão neurológica, ${ }^{8}$ ou estrutural, que ocorre quando há uma ruptura muscular parcial ou completa, como a lesão em uma concentração excêntrica. A lesão direta ocorre no local do contato, podendo causar uma laceração ou contusão. Mais de $90 \%$ de todas as lesões relacionadas ao esporte são contusões ou estiramento. ${ }^{9}$ Já as lacerações musculares são as lesões menos frequentes no esporte.

A força tênsil exercida sobre o músculo leva a um excessivo estiramento das miofibrilas e, consequentemente, a uma ruptura próxima à junção miotendínea. Os estiramentos musculares são tipicamente observados nos músculos superficiais que trabalham cruzando duas articulações, como os músculos reto femoral, semitendíneo e gastrocnêmio.

Os isquiotibiais, por exemplo, apresentam um aumento da tensão muscular à medida que o quadril flete e o joelho estende, seja no início de um sprint ou de um chute, em um clássico mecanismo de lesão muscular por contração excêntrica de um músculo biarticulado. ${ }^{10}$

\section{Classificação}

Atualmente, há vários sistemas de classificação descritos para as lesões musculares. Apenas nos últimos 10 anos, 5 sistemas diferentes foram publicados. ${ }^{11}$ Classicamente, os sistemas descrevem a lesão muscular em 3 diferentes níveis: leves, moderadas e graves (ou graus I, II e III) a partir de avaliação por imagem ${ }^{12,13}$ ou dos aspectos clínicos revelados. ${ }^{14}$ Novos sistemas estadiam as lesões de forma mais complexa, ${ }^{8,15,16}$ utilizando, além das características descritas acima, aspectos relacionados à etiologia e à localização anatômica da lesão. A - Tabela 1 mostra alguns dos modelos de classificação existentes atualmente. ${ }^{11}$

A classificação proposta por Mueller-Wohlfarht et al., ${ }^{8}$ conhecida como o Consenso de Munique, e o sistema descrito 


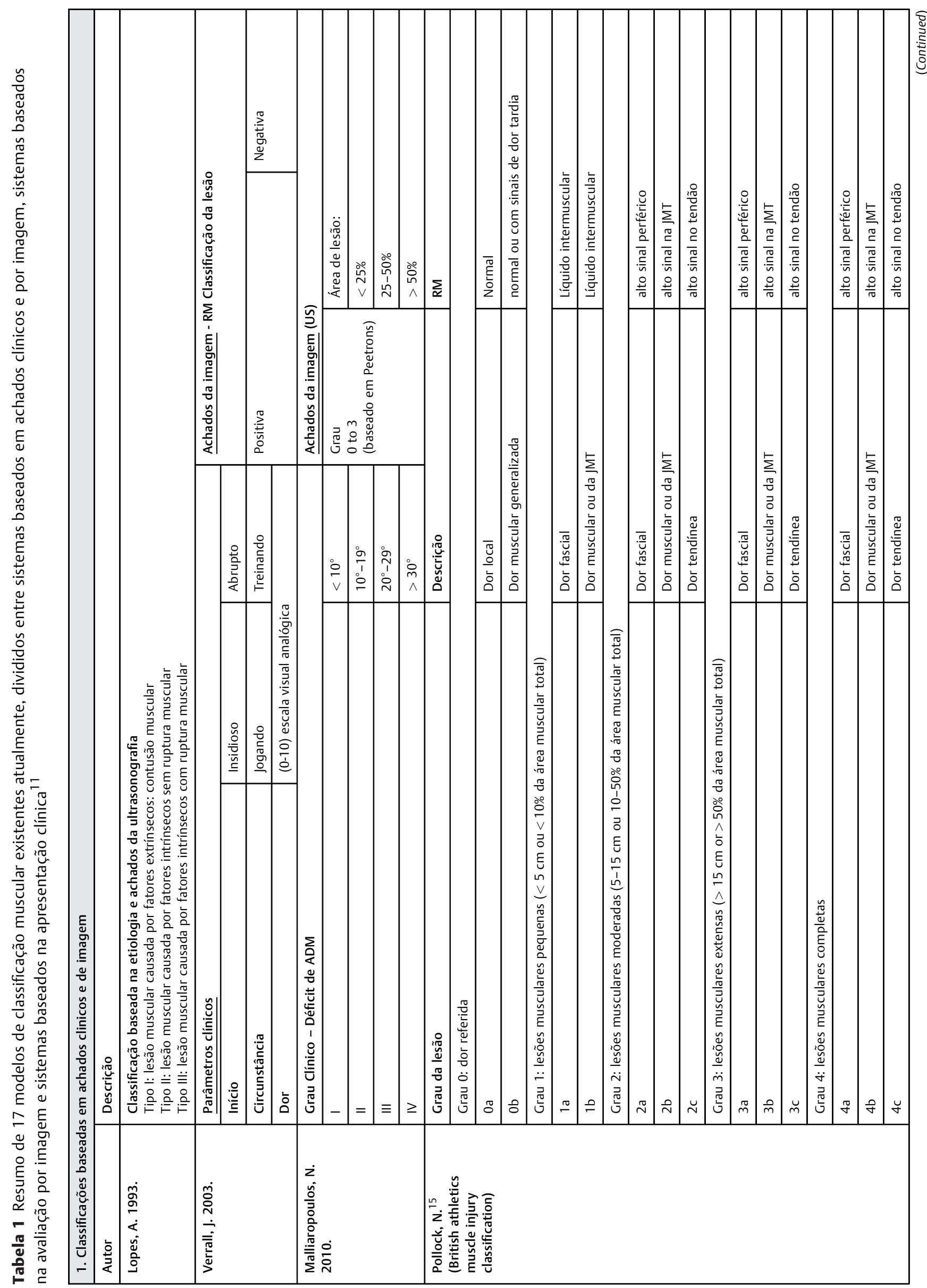


4 Lesão muscular SantAnna et al.

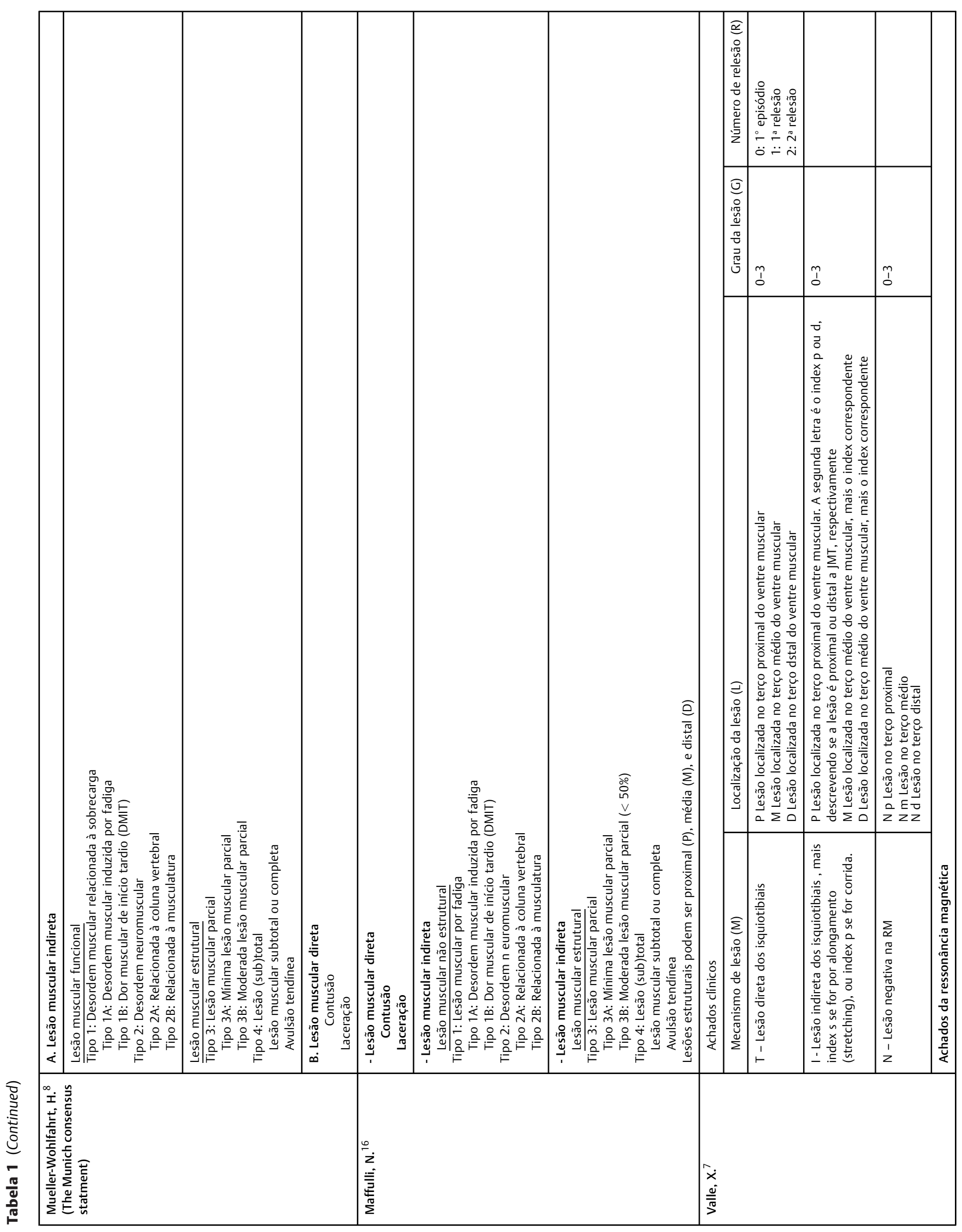


Lesão muscular SantAnna et al. 5

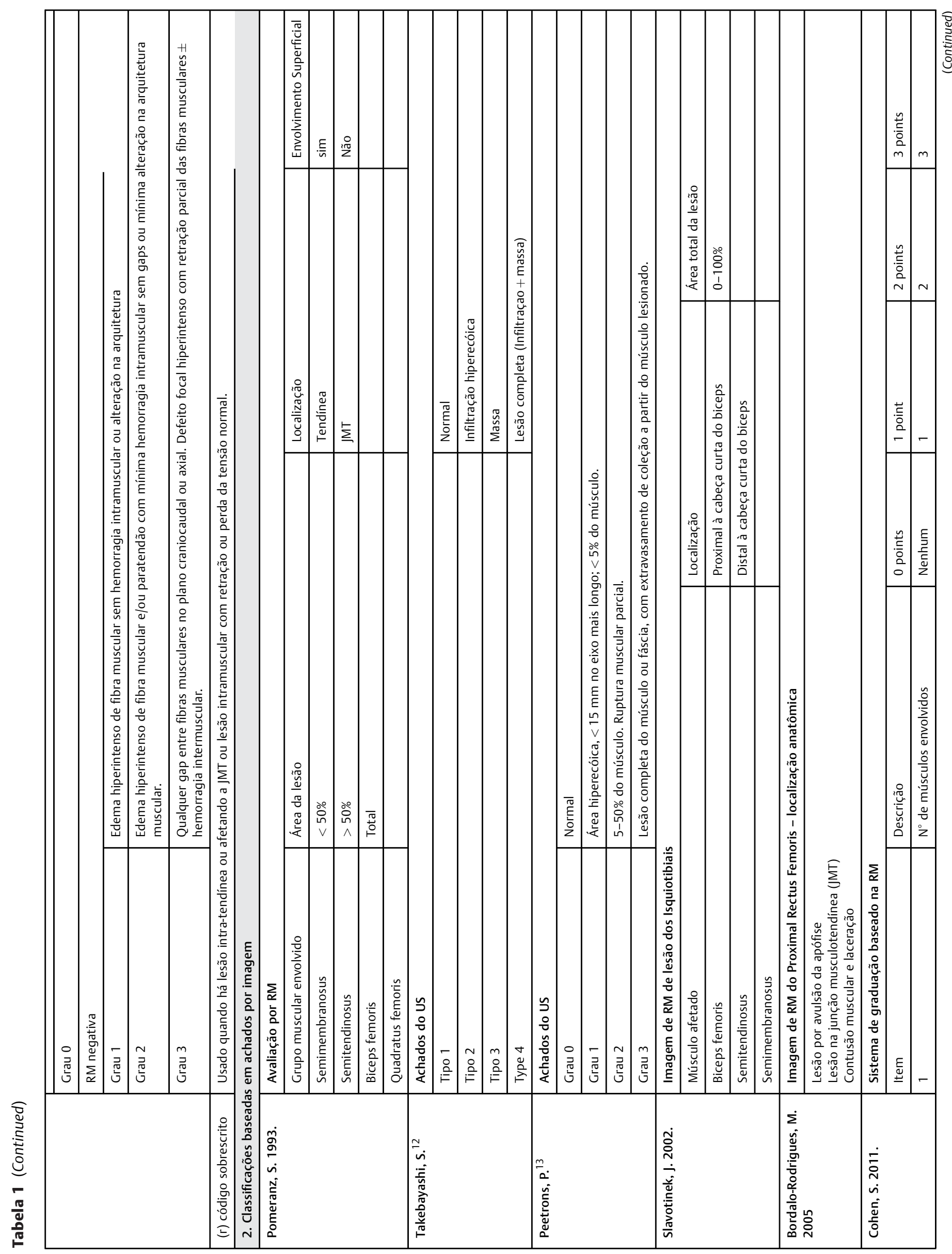




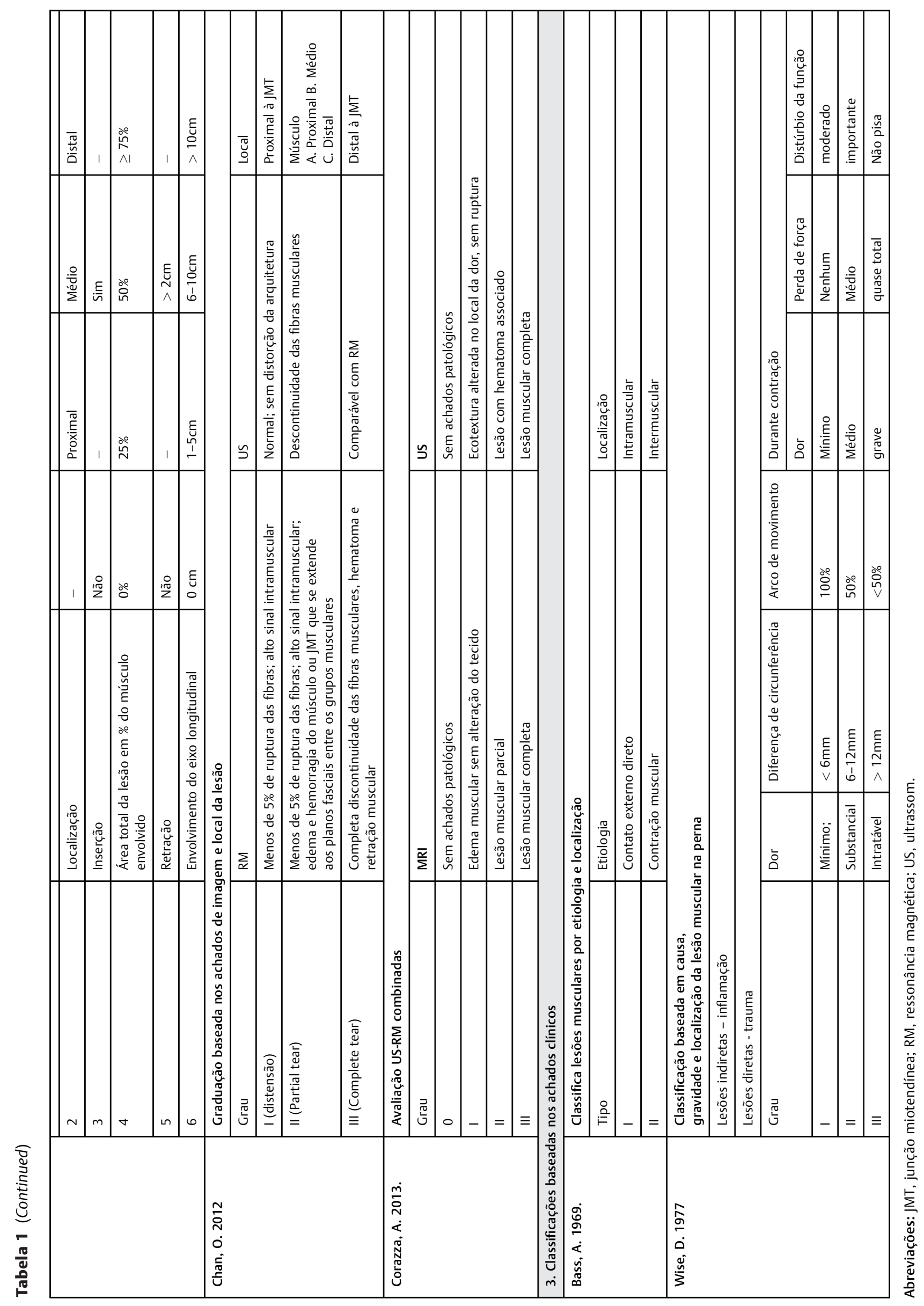


por Mafulli et al., ${ }^{16}$ consideram também aspectos etiológicos. Estes classificam a lesão muscular como direta, causada por contusão ou laceração, e indireta, subclassificada em funcional (não estrutural) ou estrutural.

O sistema descrito por Pollock et al. ${ }^{15}$ (British athletics muscle injury classification) utiliza a localização anatômica e a extensão da lesão. Avalia, através de exame de imagem, se o dano é superficial (tecido miofascial), acomete a junção miotendínea, ou se há lesão tendínea.

A classificação publicada por Valle et al. ${ }^{7}$ busca agrupar quatro características da lesão muscular em um sistema formado pelas iniciais MLG-R, relacionando a cada uma delas: mecanismo de lesão (M), localização (L), grau da lesão (G) e número de re-lesões (R).

Os sistemas descritos acima também consideram aspectos clínicos, como intensidade, tempo de início e localização da dor, para definir o tipo de lesão e fornecer um prognóstico adequado.

A classificação da lesão muscular em três níveis ainda é bastante conhecida e utilizada. Normalmente, baseia-se em achados clínicos que são relacionados à extensão da ruptura do tecido muscular, como descrito abaixo.

Estiramentos e contusões leves (grau I) representam uma lesão de apenas algumas fibras musculares com pequeno edema e desconforto, acompanhadas de nenhuma ou mínima perda de força e restrição de movimentos. Não é possível palpar-se qualquer defeito muscular durante a contração muscular. Apesar de a dor não causar incapacidade funcional significativa, a manutenção do atleta em atividade não é recomendada devido ao grande risco de aumentar a extensão da lesão. ${ }^{14}$

Estiramentos e contusões moderadas (grau II) provocam um dano maior ao músculo, com evidente perda de função (habilidade para contrair). É possível palpar-se um pequeno defeito muscular, ou gap, no sítio da lesão, e ocorre a formação de um discreto hematoma local com eventual ecmose dentro de 2 a 3 dias. A evolução para a cicatrização costuma durar de 2 a 3 semanas e, em $\sim 1$ mês, o paciente pode retornar à atividade física de forma lenta e cuidadosa. ${ }^{14}$

Uma lesão estendendo-se por toda a sessão transversa do músculo e resultando em virtualmente completa perda de função muscular e dor intensa é determinada como estiramento ou contusão grave (grau III). A falha na estrutura muscular é evidente, e a equimose costuma ser extensa, situando-se muitas vezes distante ao local da ruptura. Este tipo de lesão necessita de reabilitação intensa e por períodos longos, de até 3 a 4 meses. 0 paciente pode permanecer com algum grau de dor por meses após a ocorrência e o tratamento da lesão. ${ }^{14}$

\section{Fisiopatologia}

A cicatrização do músculo esquelético segue uma ordem constante, sem alterações importantes conforme a causa (contusão, estiramento ou laceração).

Três fases foram identificadas neste processo: destruição, reparo e remodelação. As duas últimas fases (reparo e remodelação) se sobrepõem e estão intimamente relacionadas.
Fase 1: destruição - caracterizada pela ruptura e posterior necrose das miofibrilas, pela formação do hematoma no espaço formado entre o músculo roto e pela proliferação de células inflamatórias.

Fase 2: reparo e remodelação - consiste na fagocitose do tecido necrótico, na regeneração das miofibrilas e na produção concomitante do tecido cicatricial conectivo, assim como na neoformação vascular e no crescimento neural.

Fase 3: remodelação - período de maturação das miofibrilas regeneradas, de contração e de reorganização do tecido cicatricial e da recuperação da capacidade funcional muscular.

Como as miofibrilas são fusiformes e muito compridas, há um risco iminente de que a necrose iniciada no local da lesão se estenda por todo o comprimento da fibra. Contudo, existe uma estrutura específica, chamada de banda de contração, que é uma condensação do material citoesquelético que atua como um "sistema antifogo". ${ }^{17}$

Depois que a fase de destruição diminui, o presente reparo da lesão muscular começa com dois processos simultâneos e competitivos entre si: a regeneração da miofibrila rota e a formação do tecido conectivo cicatricial. Uma progressão balanceada destes processos é pré-requisito para uma ótima recuperação da função contrátil do músculo. ${ }^{17}$

Embora as miofibrilas sejam genericamente consideradas não mitóticas, a capacidade regenerativa do músculo esquelético é garantida por um mecanismo intrínseco que restaura o aparato contrátil lesionado. Durante o desenvolvimento embrionário, um pool de reserva de células indiferenciadas, chamadas células satélites, é armazenado abaixo da lâmina basal de cada miofibrila. Em resposta à lesão, estas células primeiramente se proliferam, diferenciam-se em miofibrilas e, finalmente, juntam-se umas às outras para formar miotúbulos multinucleados. ${ }^{18}$

Com o tempo, a cicatriz formada diminui de tamanho, levando as bordas da lesão à uma aderência maior entre si. Contudo, não se sabe se a transecção das miofibrilas dos lados opostos da cicatriz vai, definitivamente, se fundir entre si ou se irá formar um septo de tecido conectivo entre elas. ${ }^{19}$

Imediatamente após a lesão muscular, o intervalo formado entre a ruptura das fibras musculares é preenchido por hematoma. Ao longo do primeiro dia, as células inflamatórias, incluindo os fagócitos, invadem o hematoma e começam a organizar o coágulo. ${ }^{20}$

A fibrina derivada de sangue e a fibronectina se intercalam para formar o tecido de granulação, uma armação inicial e ancoramento do local para os fibroblastos recrutados. ${ }^{17}$ Mais importante, este novo tecido formado provê a propriedade de tensão inicial para resistir às contrações aplicadas contra ele.

Aproximadamente 10 dias após o trauma, a maturação da cicatriz atinge um ponto em que esta não é mais o local mais frágil da lesão muscular. ${ }^{21}$

Apesar de a maioria das lesões do músculo esquelético curar sem a formação de tecido cicatricial fibroso incapacitante, a proliferação dos fibroblastos pode ser excessiva, resultando na formação de tecido cicatricial denso dentro da lesão muscular. 
Um processo vital para a regeneração do músculo lesionado é a área de vascularização. A restauração do suprimento vascular é o primeiro sinal de regeneração e pré-requisito para as recuperações morfológica e funcional subsequentes. ${ }^{22}$

\section{Diagnóstico}

O diagnóstico da lesão muscular inicia-se com uma história clínica detalhada do trauma, seguida por um exame físico com a inspeção e palpação dos músculos envolvidos, assim como os testes de função com e sem resistência externa. ${ }^{23} \mathrm{O}$ diagnóstico é fácil quando uma típica história de contusão muscular é acompanhada por um evidente edema ou uma equimose distal à lesão.

\section{Exames complementares}

Exames de imagem como ultrassom (US), tomografia computadorizada (TC) e ressonância magnética (RM) provêem informações úteis para se verificar e determinar a lesão com maior precisão. Novos métodos têm sido estudados para detectar alterações fisiológicas relacionadas à lesão muscular, como a termografia.

A ultrassonografia é tradicionalmente considerada o método de escolha para avaliação inicial da lesão muscular. É um método de imagem relativamente barato e de fácil acesso, além de possibilitar avaliar dinamicamente a contração e rotura muscular. Renoux et al. ${ }^{24}$ demonstraram haver correlação entre a gravidade da lesão muscular aguda avaliada por US com o tempo de retorno ao esporte. Este exame apresenta a desvantagem de ser examinador-dependente, ter campo de visão limitado e sensibilidade reduzida para avaliação morfológica. ${ }^{25}$

A TC já mostrou ser capaz de identificar alterações relacionadas às lesões musculares, como a presença de edema. ${ }^{26}$ Mas o fato de gerar radiação, produzir imagem estática e com pouca definição em relação à $R M,{ }^{26}$ fez com que esse método de avaliação fosse substituído.

A RM permite a avaliação detalhada da morfologia muscular devido à capacidade de gerar imagens multiplanares e de alta resolução dos tecidos moles. ${ }^{25}$ É o método de avaliação por imagem utilizado por muitos autores para definir a classificação da lesão muscular. ${ }^{8,15,16}$ A habilidade de diferenciar rupturas e edemas e de realizar o cálculo do tamanho do hematoma provou-se útil na orientação do tempo de retorno e do risco de re-lesão em atletas. ${ }^{27}$ Nas lesões crônicas, tem a capacidade de mostrar sinais de cicatrização tecidual e degeneração gordurosa. ${ }^{25}$ Técnicas avançadas de RM permitem a avaliação da microestrutura e da composição muscular. $^{25}$

A termografia médica infravermelha possibilita uma avaliação não invasiva e não radioativa da temperatura corporal. Permite detectar alterações fisiológicas que significam aumento do risco de lesões musculares, como reações inflamatórias por sobrecarga. ${ }^{28,29}$ A termografia não mostra dados de superfícies profundas e não deve ser usada como ferramenta diagnóstica única. Seu uso mostrou-se eficaz na prevenção de lesões musculares, reduzindo a incidência de lesões em jogadores de futebol profissional em $>60 \% .{ }^{30}$

\section{Tratamento}

Os atuais princípios de tratamento da lesão muscular são carentes de bases cientificas sólidas.

A mobilização precoce induz a um aumento da vascularização local na área da lesão, a uma melhor regeneração das fibras musculares e a um melhor paralelismo entre a orientação das miofibrilas regeneradas em comparação à restrição do movimento. ${ }^{31}$ Contudo, re-rupturas no sítio original do trauma são comuns se a mobilização ativa for iniciada imediatamente após a lesão. ${ }^{32}$

Um curto período de imobilização com enfaixamento adesivo firme ou similar é recomendado. Este período de repouso permite que o tecido cicatricial se conecte novamente à falha muscular. ${ }^{9}$

O paciente deve utilizar um par de muletas para as lesões musculares mais graves dos membros inferiores, principalmente nos 3 a 7 dias iniciais.

\section{Fase aguda}

O tratamento imediato para a lesão do tecido musculoesquelético ou de qualquer tecido de partes moles é conhecido como princípio Proteção, Repouso, Gelo ou Ice, Compressão e Elevação (PRICE). A justificativa do uso do princípio PRICE é por ele ser muito prático, visto que as cinco medidas clamam por minimizar o sangramento do sítio da lesão. ${ }^{23}$ Alguns autores defendem o uso do protocolo POLICE, que apresenta como principal inovação a orientação para o uso otimizado do membro lesionado na fase aguda, evitando os efeitos adversos de longos períodos de repouso. ${ }^{33}$

Colocando-se o membro lesionado em repouso logo após o trauma, previne-se uma retração muscular tardia ou a formação de um gap muscular maior por se reduzir o tamanho do hematoma e, subsequentemente, o tamanho do tecido conectivo cicatricial. Com relação ao uso do gelo, mostrou-se que o uso precoce de crioterapia está associado a um hematoma significativamente menor no gap das fibras musculares rompidas, a menor inflamação ${ }^{34}$ e a regeneração acelerada. $^{35}$

É recomendada a combinação do uso de gelo e compressão por turnos de 15 a 20 minutos, repetidos em intervalos de 30 a 60 minutos, visto que este tipo de protocolo resulta em 3 a $7^{\circ} \mathrm{C}$ de decaimento da temperatura intramuscular e a $50 \%$ de redução do fluxo sanguíneo intramuscular. ${ }^{36}$

Finalmente, a elevação do membro acima do nível do coração resulta na diminuição da pressão hidrostática, reduzindo o acúmulo de líquido no espaço intersticial.

\section{Medicação}

Existem poucos estudos controlados utilizando antiinflamatórios não hormonais (AINHs) ou glicocorticoides no tratamento de lesões musculares em humanos. O'Grady et al. ${ }^{37}$ reportaram que o uso de anti-inflamatórios no tratamento da necrose in situ, o tipo mais leve de lesão muscular, em curto prazo, resulta em uma melhora transitória na recuperação da lesão muscular induzida pelo exercício. Apesar do fato da falta de evidência, os efeitos dos AINHs têm sido bem documentados. Järvinen ${ }^{9}$ defendeu que o uso em curto 
período na fase precoce da recuperação diminuiu a reação inflamatória celular sem efeitos colaterais no processo de cicatrização, na força tênsil ou na habilidade de contração muscular.

Além disso, os AINHs não retardam as habilidades ativadas pelas células satélites em se proliferar ou a formação dos miotúbulos. ${ }^{38}$ Contudo, o uso crônico parece ser prejudicial no modelo de contração excêntrica nas lesões por estiramento, como discutido por Mishra et al. ${ }^{39}$

Com relação ao uso de glicocorticoides, foram reportados atrasos na eliminação do hematoma e do tecido necrótico, retardo no processo de regeneração e redução da força biomecânica do músculo lesionado. ${ }^{40}$

\section{Tratamento pós-fase aguda}

1. Treinamento isométrico (contração muscular na qual o comprimento do músculo se mantém constante e a tensão muda) pode ser iniciado sem o uso de pesos e, posteriormente, com o acréscimo deles. Especial atenção deve ser tomada para garantir que todos os exercícios isométricos sejam realizados sem dor.

2. Treinamento isotônico (contração muscular na qual o tamanho do músculo muda e a tensão se mantém) pode ser iniciado quando o treino isométrico for realizado sem dor com cargas resistidas.

3. O exercício isocinético com carga mínima pode ser iniciado uma vez que os dois exercícios anteriores sejam realizados sem dor.

A aplicação local de calor ou "terapia de contraste" (quente e frio) pode ser de valor, acompanhada de cuidadoso alongamento passivo e ativo do músculo afetado. Ressalta-se que qualquer atividade de reabilitação deve ser iniciada com o aquecimento adequado do músculo lesionado. ${ }^{41}$

Outra razão para o alongamento é distender o tecido cicatricial maduro durante a fase na qual ele ainda é plástico. Alongamentos da cicatriz sem dor podem ser adquiridos por estiramentos graduais, começando com turnos de 10 a 15 segundos e, então, progredindo para períodos de até 1 minuto.

Contudo, se os sintomas causados pela lesão não melhorarem em entre 3 e 5 dias após o trauma, deve-se considerar a possibilidade da existência de um hematoma intramuscular ou de um tecido lesionado extenso que necessitará de atenção especial. A punção ou aspiração do hematoma pode ser necessária.

\section{Ultrassom}

O US terapêutico é difusamente recomendado e utilizado no tratamento da lesão muscular; alguns autores defendem que há vaga evidência científica de sua efetividade. ${ }^{42} \mathrm{O}$ fato de o US produzir micromassagens pelas ondas de alta frequência, aparentemente, funciona para o alívio da dor. Engelmann et al. ${ }^{43}$ mostraram a redução da atividade inflamatória com o uso de ultrassom pulsado. A ultrassonografia também pode ser útil para a realização de procedimentos terapêuticos e no tratamento cirúrgico das lesões musculares. $^{44,45}$

\section{Tratamento cirúrgico}

Há indicações precisas nas quais a intervenção cirúrgica é necessária. Estas indicações incluem: pacientes com grandes hematomas intramusculares, lesões ou roturas completas (grau III) com pouca ou nenhuma musculatura agonista associada e lesões parciais nas quais mais da metade do músculo esteja roto. ${ }^{46,47}$

A intervenção cirúrgica também pode ser considerada se o paciente se queixa de dor persistente à extensão por $>4$ a 6 meses, particularmente se houver déficit de extensão. Neste caso em particular, deve-se suspeitar de adesões por cicatrizes restringindo o movimento muscular no sítio da lesão.

Após o reparo cirúrgico, o músculo deve ser protegido por uma bandagem elástica ao redor do membro a fim de promover relativa imobilidade e compressão. A duração da imobilização, naturalmente, depende da gravidade do trauma. Pacientes com rotura completa do músculo quadríceps ou gastrocnêmio são instruídos a não colocarem carga no membro por pelo menos 4 semanas.

Se o gap ou falha muscular for excepcionalmente largo, a porção desnervada pode gerar um déficit neurológico permanente e consequente atrofia muscular. ${ }^{21} 0$ reparo cirúrgico nestas circunstâncias aumenta a chance de reinervação e o desenvolvimento de tecido cicatricial espesso pode ser evitado.

\section{Novas perspectivas}

O uso terapêutico de fatores de crescimento e a terapia gênica, sozinhos ou em combinação, e a aplicação de células-tronco proporcionam as últimas e mais promissoras opções terapêuticas existentes. Contudo, há, no momento, necessidade de maior validação científica para a sua intensificação no tratamento de lesões do músculo esquelético.

Os fatores de crescimento e citocinas são potentes ativadores mitogênicos para inúmeras células, incluindo as células precurosas miogênicas (MPCs, na sigla em inglês) durante a regeneração das células musculares lesionadas. ${ }^{48}$ Portanto, são opções terapêuticas promissoras para auxiliar na recuperação da musculatura esquelética.

Em relação às células tronco, mostrou-se recentemente que, em resposta à lesão, não somente as células tecidoespecíficas, como também as células tronco não musculares participam do processo de reparo. ${ }^{49}$

Os primeiros passos da terapia gênica já foram dados. Estudos bem-sucedidos têm demonstrado bons resultados do uso de células-tronco em tecido muscular no tratamento de distrofias musculares, lesões musculares cardíacas e na incontinência urinária. ${ }^{10,50}$ Os estudos futuros irão demonstrar em que esfera a terapia gênica poderá tornar realidade as atuais expectativas em relação ao tratamento dos traumas musculares.

\section{Apresentação Clínica}

\section{Lesão muscular do quadríceps}

A lesão distal do quadríceps é uma lesão pouco comum, ocorrendo mais frequentemente em indivíduos $>40$ anos. $^{51}$ A lesão pode ocorrer por motivo de trauma direto, mas 
classicamente é relatada como uma contração excêntrica forçada em posição de leve flexão do membro inferior na tentativa de se recuperar o equilíbrio em um momento de queda.

As roturas espontâneas e as roturas bilaterais foram descritas em atletas com distúrbios metabólicos sistêmicos e com uso de esteroides. ${ }^{52}$

O diagnóstico de rotura é baseado nos achados clínicos. Tipicamente, o paciente apresenta, após uma queda com os joelhos fletidos, uma dor aguda acima da patela e incapacidade de se manter na posição ortostática sem auxílio.

Durante o exame físico, o paciente não é capaz de estender ativamente o joelho e, muitas vezes, existe um intervalo palpável acima da patela, conhecido como o "sinal do sulco" ou gap test. Os pacientes são capazes de fletir ativamente o joelho e possuem flexão e extensão passivas totais do joelho.

A radiografia simples é uma ferramenta barata para o diagnóstico da rotura. Apesar de não mostrar uma alteração específica da lesão, ela evidencia sinais indiretos da rotura. Edema de partes moles, derrame articular, calcificações, sombra da rotura do quadríceps e patela baixa são todos sinais indiretos vistos na radiografia simples. ${ }^{53}$

O US é outro método barato para se diagnosticar a lesão muscular. A RM é particularmente útil para melhor visualização, precisão da localização e extensão da lesão e dos detalhes anatômicos para a programação pré-operatória.

Para as roturas musculares completas, o tratamento é cirúrgico. O tratamento cirúrgico precoce nestes casos está associado aos melhores resultados funcionais. ${ }^{54}$ Já o atraso no reparo cirúrgico está associado a um período de fisioterapia prolongado, flexão inadequada e perda de extensão total do joelho. ${ }^{54}$ Após o reparo cirúrgico, os pacientes têm o joelho imobilizado por 4 a 6 semanas.

\section{Lesão dos músculos isquiotibiais}

Os músculos isquiotibiais são os menos alongados do membro inferior e, por este motivo, são mais facilmente lesionados durante a contração muscular excêntrica.

A gravidade da lesão é geralmente negligenciada, especialmente na fase aguda.

O estiramento dos isquiotibiais é a lesão mais comum nos atletas. $^{55}$

O diagnóstico da lesão é normalmente realizado a partir de um alto índice de suspeita clínica e exame clínico cuidadoso. A RM é valiosa para se diferenciar entre uma lesão completa ou incompleta e para o planejamento do tratamento.

A rotura completa dos músculos isquiotibiais proximalmente em sua origem é rara. A condução do caso varia entre o tratamento conservador com um imobilizador em flexão e o reparo cirúrgico em um segundo momento. Embora o reparo cirúrgico em um segundo tempo possa apresentar bons resultados, o reparo precoce permite uma reabilitação funcional mais rápida e evita o sintoma neurológico potencial de ciática glútea.

\section{Lesão da musculatura adutora}

O grupo muscular adutor atua em conjunto com os músculos abdominais baixos para estabilizar a pelve durante as atividades dos membros inferiores. Os atletas que participam de atividades que requerem chutes repetitivos, arranques ou mudanças de direção frequentes possuem maior incidência de dor crônica na topografia dos adutores. ${ }^{56}$

Há evidências de que atletas com desequilíbrio entre a musculatura adutora e a da parede abdominal estão mais propensos a adquirirem pubalgia durante a temporada. ${ }^{57} \mathrm{~A}$ fraqueza dos músculos adutores e a diminuição da amplitude do movimento do quadril também estão relacionadas à pubalgia. $^{58}$

Tipicamente, os pacientes apresentam um dolorimento na região da virilha ou dor medial na coxa, podendo relatar ou não um fator desencadeante. Ao exame físico, apresenta-se uma dor à palpação com edema focal ao longo dos músculos adutores, além de diminuição da força muscular e dor ao exercício resistido de adução dos quadris.

O diagnóstico pode ser realizado com os achados do exame físico. Contudo, a RM com contraste pode ser útil para se confirmar o diagnóstico ou realizar-se o diagnóstico diferencial entre osteíte púbica e hérnia do esporte. ${ }^{59}$

O tratamento inicial é conservador. A infiltração da entese do adutor longo pode ser útil para o tratamento refratário. Nos casos de rotura aguda, o reparo cirúrgico aberto com colocação de âncoras e sutura tem sido descrito com bons resultados. $^{60}$

Os pacientes poderão retomar o esporte após o retorno ao padrão prévio de fortalecimento, a recuperação da amplitude de movimento do quadril e a resolução do quadro álgico. Devido à predisposição da lesão do adutor ser causada pelo desequilíbrio muscular, deve-se ter atenção para o fortalecimento da musculatura a fim de se prevenir novas lesões.

\section{Lesão dos músculos gastrocnêmios}

Assim como os músculos isquiotibiais e quadríceps, o gastrocnêmio é propenso a lesões, pois cruza duas articulações.

A cabeça medial do gastrocnêmio é mais comumente lesionada do que a lateral, visto que esta é mais ativa. ${ }^{61} \mathrm{~A}$ trombose venosa profunda pode estar associada ou ser um diagnóstico diferencial de dor na panturrilha, assim como a tromboflebite. ${ }^{62}$

O termo tennis leg tem sido utilizado para se descrever a dor e a lesão na panturrilha. O termo é atribuído ao movimento do saque no tênis, no qual há uma extensão completa do joelho associada a uma dorsiflexão do tornozelo abrupta, provocando o máximo alongamento da panturrilha. Contudo, esta lesão foi descrita também em atletas jovens durante períodos de exercícios extenuantes como basquete, corrida e musculação. ${ }^{63}$

O aparecimento da dor é repentino, com edema focal e ecmose da panturrilha. Classicamente, o tennis leg é referido como uma lesão da junção miotendínea distal, embora a lesão proximal possa ocorrer.

Por causa da natureza superficial da lesão, a avaliação ultrassonográfica é confiável, possibilita facilmente excluir a presença de trombose venosa profunda e provê a aspiração de coleções líquidas guiadas por imagem.

O tratamento da maioria das lesões do gastrocnêmio é conservador. Ocasionalmente, deve-se realizar cirurgia para 
se drenar hematomas, reparar uma lesão grau III ou realizar uma descompressão compartimental nos casos de síndrome compartimental.

\section{Lesão dos músculos peitorais}

O músculo peitoral maior (PM) apresenta uma anatomia complexa. $\mathrm{O}$ tendão é bilaminar (camadas anterior e posterior) e o ventre muscular é composto da cabeça clavicular e da cabeça esternal, dividida em sete segmentos. ${ }^{64}$

Casos de lesão do músculo peitoral maior têm se tornado mais comuns nos últimos anos. O principal motivo é o aumento da prática de esportes com levantamento de peso (weight lifting). O mecanismo mais comum é a lesão indireta durante a fase excêntrica no levantamento de peso em supino. ${ }^{65}$ Essa lesão também é frequente em esportes como ginástica olímpica, luta greco-romana e windsurfe. ${ }^{66}$

A perda de força de adução do membro superior leva à necessidade de tratamento cirúrgico, tanto para as lesões agudas (até 3 semanas), como crônicas (após 3 semanas). Normalmente, o tratamento na fase aguda é o reparo próximo à inserção humeral. Nas lesões crônicas, pode ser necessária a reconstrução do tendão PM com uso de tendões flexores. ${ }^{66}$

Lesões do músculo peitoral menor são raras e, muitas vezes, são confundidas com lesão do PM. O tratamento conservador foi eficaz nos poucos casos relatados desse tipo de lesão. ${ }^{67}$

\section{Lesão distal do músculo bíceps braquial}

O músculo bíceps braquial é composto pela cabeça longa, com origem no tubérculo supraglenoidal e com atuação na supinação, e pela cabeça curta, a partir do processo coracoide, e com maior atuação na flexão do cotovelo. A inserção distal é na tuberosidade radial. ${ }^{68}$

A ruptura distal é incomum, ocorrendo em $10 \%$ de todas as lesões do bíceps, acontecendo principalmente no membro dominante em pacientes masculinos. O mecanismo é a contração excêntrica durante a extensão do cotovelo. ${ }^{69}$

Estudos biomecânicos mostram redução da força e da resistência da supinação e uma menor perda de força da flexão do cotovelo. O tratamento conservador é normalmente indicado para pacientes sedentários ou com baixa demanda. ${ }^{68} \mathrm{O}$ tratamento cirúrgico é realizado através da reinserção na tuberosidade radial com o uso de botões corticais, âncoras, parafuso de interferência ou sutura transóssea. ${ }^{68}$

\section{Considerações Finais}

A compreensão dos mecanismos fisiopatológicos que regulam a reparação muscular e sua adaptação ao treinamento físico são essenciais para o profissional que se propõe a tratar destes pacientes. Estas são a base para o desenvolvimento dos meios de prevenção de lesões e para o tratamento adequado e reabilitação das lesões instaladas.

Em relação ao tempo apropriado de retorno ao treino específico para o esporte, a decisão pode ser baseada em duas simples e pouco onerosas medidas: a habilidade de alongar o músculo lesionado tanto quanto o lado contralateral sadio e ausência de dor no músculo lesionado em movimentos básicos.

Quando o paciente refere alcançar este ponto na recuperação, a permissão de se iniciar gradualmente os exercícios específicos para o esporte é garantida. Contudo, sempre deve ser enfatizado que a fase final de reabilitação deve ser realizada sob supervisão de profissional capacitado.

\section{Suporte Financeiro}

Não houve suporte financeiro de fontes públicas, comerciais, ou sem fins lucrativos.

Conflito de Interesses

Os autores declaram não haver conflito de interesses.

\section{Referências}

1 Herring SA, Nilson KL. Introduction to overuse injuries. Clin Sports Med 1987;6(02):225-239

2 Edouard P, Branco P, Alonso JM. Muscle injury is the principal injury type and hamstring muscle injury is the first injury diagnosis during top-level international athletics championships between 2007 and 2015. Br J Sports Med 2016;50(10): 619-630

3 Ekstrand J, Hägglund M, Waldén M. Epidemiology of muscle injuries in professional football (soccer). Am J Sports Med 2011; 39(06):1226-1232

4 Jones A, Jones G, Greig N, et al. Epidemiology of injury in English Professional Football players: A cohort study. Phys Ther Sport 2019;35:18-22

5 Aasa U, Svartholm I, Andersson F, Berglund L. Injuries among weightlifters and powerlifters: a systematic review. Br J Sports Med 2017;51(04):211-219

6 Pedrinelli A, Fernandes TL, Thiele E, Teixeira W. Lesão muscular ciências básicas, fisiopatologia, diagnóstico e tratamento. In: Alves JúniorW, Fernandes T, eds. Programa de Atualização em Traumatologia e Ortopedia (PROATO). Porto Alegre: Artmed; 2006:10

7 Valle X, Alentorn-Geli E, Tol JL, et al. Muscle Injuries in Sports: A New Evidence-Informed and Expert Consensus-Based Classification with Clinical Application. Sports Med 2017;47(07):1241-1253

8 Mueller-Wohlfahrt HW, Haensel L, Mithoefer K, et al. Terminology and classification of muscle injuries in sport: the Munich consensus statement. Br J Sports Med 2013;47(06):342-350

9 Järvinen MJ, Lehto MU. The effects of early mobilisation and immobilisation on the healing process following muscle injuries. Sports Med 1993;15(02):78-89

10 Almeida A, Dorileo C, Thiele E, SantAnna JPC, Costa PHP. Lesões musculares. In: Cristante AF, Brandão GF, editores. Programa de Atualização em Traumatologia e Ortopedia (PROATO). Ciclo 12 Porto Alegre: Artmed; 2015:85-110

11 Santanna JPC, de Almeida AM, Pedrinelli A, Hernandez AJ, Fernandes TL. Quality assessment of muscle injury classification in sports: A systematic literature review. Muscles Ligaments Tendons J 2018;8(02):206-221

12 Takebayashi S, Takasawa H, Banzai Y, et al. Sonographic findings in muscle strain injury: clinical and MR imaging correlation. J Ultrasound Med 1995;14(12):899-905

13 Peetrons P. Ultrasound of muscles. Eur Radiol 2002;12(01):35-43

14 Hernandez AJ. Distensões e rupturas musculares. In: Camanho GL, editor. Patologia do Joelho. Sao Paulo: Sarvier; 1996:132-138

15 Pollock N, James SL, Lee JC, Chakraverty R. British athletics muscle injury classification: a new grading system. Br J Sports Med 2014; 48(18):1347-1351 
16 Maffulli N, Oliva F, Frizziero A, et al. ISMuLT Guidelines for muscle injuries. Muscles Ligaments Tendons J 2014;3(04):241-249

17 Hurme T, Kalimo H, Lehto M, Järvinen M. Healing of skeletal muscle injury: an ultrastructural and immunohistochemical study. Med Sci Sports Exerc 1991;23(07):801-810

18 Rantanen J, Hurme T, Lukka R, Heino J, Kalimo H. Satellite cell proliferation and the expression of myogenin and desmin in regenerating skeletal muscle: evidence for two different populations of satellite cells. Lab Invest 1995;72(03):341-347

19 Aärimaa V, Kääriäinen $M$, Vaittinen $S$, et al. Restoration of myofiber continuity after transection injury in the rat soleus. Neuromuscul Disord 2004;14(07):421-428

20 Cannon JG, St Pierre BA. Cytokines in exertion-induced skeletal muscle injury. Mol Cell Biochem 1998;179(1-2):159-167

21 Kääriäinen M, Kääriäinen J, Järvinen TL, Sievänen $H$, Kalimo $H$, Järvinen M. Correlation between biomechanical and structural changes during the regeneration of skeletal muscle after laceration injury. J Orthop Res 1998;16(02):197-206

22 Järvinen M. Healing of a crush injury in rat striated muscle. 3. A micro-angiographical study of the effect of early mobilization and immobilization on capillary ingrowth. Acta Pathol Microbiol Scand A 1976;84(01):85-94

23 Fernandes TL, Pedrinelli A, Hernandez AJ. Dor na coxa e na perna. In: Nobrega A, editor. Manual de Medicina do Esporte. Sao Paulo: Atheneu; 2009:140-141

24 Renoux J, Brasseur J-L, Wagner M, et al. Ultrasound-detected connective tissue involvement in acute muscle injuries in elite athletes and return to play: The French National Institute of Sports (INSEP) study. J Sci Med Sport 2019;22(06):641-646

25 Crema MD, Yamada AF, Guermazi A, Roemer FW, Skaf AY. Imaging techniques for muscle injury in sports medicine and clinical relevance. Curr Rev Musculoskelet Med 2015;8(02):154-161

26 Davis KW. Imaging of the hamstrings. Semin Musculoskelet Radiol 2008;12(01):28-41

27 Ekstrand J, Healy JC, Waldén M, Lee JC, English B, Hägglund M. Hamstring muscle injuries in professional football: the correlation of MRI findings with return to play. Br J Sports Med 2012;46 (02):112-117

28 Côrte ACR, Hernandez AJ. Termografia Médica Infravermelha Aplicada à Medicina do Esporte. Rev Bras Med Esporte 2016;22 (04):315-319

29 Bandeira F, Neves EB, Barroso GC, Nohama P. Métodos de apoio ao diagnóstico de lesões musculares. Rev Bras Inov Tecnol Saúde 2013;3(03):27-44

30 Côrte AC, Pedrinelli A, Marttos A, Souza IFG, Grava J, Hernandez AJ. Infrared thermography study as a complementary method of screening and prevention of muscle injuries: pilot study. BMJ Open Sport Exerc Med 2019;5(01):e000431

31 Järvinen M. Healing of a crush injury in rat striated muscle. 2. a histological study of the effect of early mobilization and immobilization on the repair processes. Acta Pathol Microbiol Scand A 1975;83(03):269-282

32 Lehto M, Duance VC, Restall D. Collagen and fibronectin in a healing skeletal muscle injury. An immunohistological study of the effects of physical activity on the repair of injured gastrocnemius muscle in the rat. J Bone Joint Surg Br 1985;67(05): $820-828$

33 Bleakley CM, Glasgow P, MacAuley DC. PRICE needs updating, should we call the POLICE? Br J Sports Med 2012;46(04):220-221

34 Puntel GO, Carvalho NR, Amaral GP, et al. Therapeutic cold: An effective kind to modulate the oxidative damage resulting of a skeletal muscle contusion. Free Radic Res 2011;45(02):125-138

35 Hurme T, Rantanen J, Kaliomo H. Effects of early cryotherapy in experimental skeletal muscle injury. Scand J Med Sci Sports 1993; 3(01):46-51

36 Thorsson O, Hemdal B, Lilja B, Westlin N. The effect of external pressure on intramuscular blood flow at rest and after running. Med Sci Sports Exerc 1987;19(05):469-473
37 O'Grady M, Hackney AC, Schneider K, et al. Diclofenac sodium (Voltaren) reduced exercise-induced injury in human skeletal muscle. Med Sci Sports Exerc 2000;32(07):1191-1196

38 Thorsson O, Rantanen J, Hurme T, Kalimo H. Effects of nonsteroidal antiinflammatory medication on satellite cell proliferation during muscle regeneration. Am J Sports Med 1998;26(02): 172-176

39 Mishra DK, Fridén J, Schmitz MC, Lieber RL. Anti-inflammatory medication after muscle injury. A treatment resulting in shortterm improvement but subsequent loss of muscle function. J Bone Joint Surg Am 1995;77(10):1510-1519

40 Beiner JM, Jokl P, Cholewicki J, Panjabi MM. The effect of anabolic steroids and corticosteroids on healing of muscle contusion injury. Am J Sports Med 1999;27(01):2-9

41 Magnusson SP, Simonsen EB, Aagaard P, Gleim GW, McHugh MP, Kjaer M. Viscoelastic response to repeated static stretching in the human hamstring muscle. Scand J Med Sci Sports 1995;5(06): 342-347

42 Wilkin LD, Merrick MA, Kirby TE, Devor ST. Influence of therapeutic ultrasound on skeletal muscle regeneration following blunt contusion. Int J Sports Med 2004;25(01):73-77

43 Engelmann J, Vitto MF, Cesconetto PA, et al. Pulsed ultrasound and dimethylsulfoxide gel treatment reduces the expression of proinflammatory molecules in an animal model of muscle injury. Ultrasound Med Biol 2012;38(08):1470-1475

44 Wood JP, Beaulieu CF. Musculotendinous Injuries: Sonographicguided Interventions. Semin Musculoskelet Radiol 2017;21(04): 470-484

45 Ballard DH, Campbell KJ, Hedgepeth KB, et al. Anatomic guide and sonography for surgical repair of leg muscle lacerations. J Surg Res 2013;184(01):178-182

46 Almekinders LC. Results of surgical repair versus splinting of experimentally transected muscle. J Orthop Trauma 1991;5(02): 173-176

47 Kujala UM, Orava S, Järvinen M. Hamstring injuries. Current trends in treatment and prevention. Sports Med 1997;23(06): 397-404

48 Best TM, Shehadeh SE, Leverson G, Michel JT, Corr DT, Aeschlimann D. Analysis of changes in mRNA levels of myoblast- and fibroblast-derived gene products in healing skeletal muscle using quantitative reverse transcription-polymerase chain reaction. J Orthop Res 2001;19(04):565-572

49 LaBarge MA, Blau HM. Biological progression from adult bone marrow to mononucleate muscle stem cell to multinucleate muscle fiber in response to injury. Cell 2002;111(04):589-601

50 Maclean S, Khan WS, Malik AA, Anand S, Snow M. The potential of stem cells in the treatment of skeletal muscle injury and disease. Stem Cells Int 2012;2012:282348

51 Siwek CW, Rao JP. Ruptures of the extensor mechanism of the knee joint. J Bone Joint Surg Am 1981;63(06):932-937

52 Liow RY, Tavares S. Bilateral rupture of the quadriceps tendon associated with anabolic steroids. Br J Sports Med 1995;29(02): 77-79

53 Stephens BO, Anderson GVJ Jr. Simultaneous bilateral quadriceps tendon rupture: a case report and subject review. J Emerg Med 1987;5(06):481-485

54 Walker LG, Glick H. Bilateral spontaneous quadriceps tendon ruptures. A case report and review of the literature. Orthop Rev 1989;18(08):867-871

55 Blasier RB, Morawa LG. Complete rupture of the hamstring origin from a water skiing injury. Am J Sports Med 1990;18 (04):435-437

56 Cunningham PM, Brennan D, O'Connell M, MacMahon P, O'Neill P, Eustace $S$. Patterns of bone and soft-tissue injury at the symphysis pubis in soccer players: observations at MRI. AJR Am J Roentgenol 2007; 188(03):W291-6

57 Almeida MO, Silva BN, Andriolo RB, Atallah ÁN, Peccin MS. Conservative interventions for treating exercise-related 
musculotendinous, ligamentous and osseous groin pain. Cochrane Database Syst Rev 2013;(06):CD009565

58 Verrall GM, Slavotinek JP, Barnes PG, Esterman A, Oakeshott RD, Spriggins AJ. Hip joint range of motion restriction precedes athletic chronic groin injury. J Sci Med Sport 2007;10(06):463-466

59 Schilders E, Bismil Q, Robinson P, O'Connor PJ, Gibbon WW, Talbot JC. Adductor-related groin pain in competitive athletes. Role of adductor enthesis, magnetic resonance imaging, and entheseal pubic cleft injections. J Bone Joint Surg Am 2007;89(10):2173-2178

60 Vogt S, Ansah P, Imhoff AB. Complete osseous avulsion of the adductor longus muscle: acute repair with three fiberwire suture anchors. Arch Orthop Trauma Surg 2007;127(08):613-615

61 Segal RL, Song AW. Nonuniform activity of human calf muscles during an exercise task. Arch Phys Med Rehabil 2005;86(10):2013-2017

62 Bianchi S, Martinoli C, Abdelwahab IF, Derchi LE, Damiani S. Sonographic evaluation of tears of the gastrocnemius medial head ("tennis leg"). J Ultrasound Med 1998;17(03):157-162

63 McClure JG. Gastrocnemius musculotendinous rupture: a condition confused with thrombophlebitis. South Med J 1984;77(09): $1143-1145$
64 ElMaraghy AW, Devereaux MW. A systematic review and comprehensive classification of pectoralis major tears. J Shoulder Elbow Surg 2012;21(03):412-422

65 de Castro Pochini A, Ejnisman B, Andreoli CV, et al. Exact moment of tendon of pectoralis major muscle rupture captured on video. Br J Sports Med 2007;41(09):618-619, discussion 619

66 Pochini AC, Rodrigues MSB, Yamashita L, Belangero PS, Andreoli $\mathrm{CV}$, Ejnisman B. Surgical treatment of pectoralis major muscle rupture with adjustable cortical button. Rev Bras Ortop 2017;53 (01):60-66

67 Vance DD, Qayyum U, Jobin CM. Rare Isolated Pectoralis Minor Tear from a Noncontact Injury: Case Report and Review of the Literature. Case Rep Orthop 2019;2019:3605187

68 Cerciello S, Visonà E, Corona K, Ribeiro Filho PR, Carbone S. The Treatment of Distal Biceps Ruptures: An Overview. Joints 2019;6 (04):228-231

69 Krych AJ, Kohen RB, Rodeo SA, Barnes RP, Warren RF, Hotchkiss RN. Acute brachialis muscle rupture caused by closed elbow dislocation in a professional American football player. J Shoulder Elbow Surg 2012;21(07):e1-e5 